\title{
Estimativa de coeficientes de escoamento superficial na bacia hidrográfica do rio Atuba: Curitiba e região metropolitana - Paraná/ Brasil
}

\author{
Estimated runoff coefficients for Atuba river hydrographic basin: Curitiba and metropolitan region - \\ Paraná/Brazil
}

FABRIZIA GIOPPO NUNES*, ALBERTO PIO FIORI**, GIACOMO FIRPO***

* Universidade Federal de Goiás. fabriziagioppo@iesa.ufg.br

** Universidade Federal do Paraná

*** Universidade de Siena

\begin{abstract}
Resumo
O trabalho apresenta os resultados da aplicação do método do Soil Conservation Service (SCS), atrelado à utilização de técnicas de tratamento de dados e confecção de mapas temáticos em ambiente SIG. Tem como objetivo principal avaliar a variação temporal e espacial dos coeficientes de escoamento superficial ( $C$ ), ocasionado pela impermeabilização do solo, na bacia hidrográfica do rio Atuba. A avaliação temporal e espacial foi realizada em três períodos distintos de urbanização: I) início da década de 60, ano de 1962, quando a bacia estava quase que em seu estado natural; II) ano de 1980, início do processo de urbanização e; III) ano 2000 , período em que se observa um acelerado aumento das áreas urbanizadas. O método do SCS calcula o coeficiente $\mathrm{C}$ a partir das diversas percentagens de impermeabilização da cobertura superficial do terreno e, das características físicas e umidade antecedente, dos diferentes grupos hidrológicos de solos, encontrados em uma bacia hidrográfica. Como resultado final obteve-se a quantificação dos índices de armazenamento superficial dos solos e dos índices de escoamento superficial além, da interpolação, em ambiente SIG, dos mapas de cobertura superficial do terreno com o mapa de solo para a elaboração do mapa da análise multitemporal dos coeficientes de escoamento superficial.
\end{abstract}

Palavras-chave: coeficiente de escoamento, impermeabilização, mapeamento, urbanização, Rio Atuba.

\begin{abstract}
This paper presents results from the Soil Conservation Service method (SCS), including data treatment and thematically maps done under GIS environment applied. Its aiming is evaluate the temporal and spatial variation of the runoff coefficient (C) caused by impermeable surfaces in the river basin Atuba. The temporal and spatial evaluation was done studying three different periods of urbanization: (a) beginner of 60 years, when the basin could be considered in its natural state; (b) in 1980, during the initial process of urbanization and (c) in 2000, when some areas of the basin remains close to the natural state but is easy to observe a fast increasing in urbanization process. In the methodology developed by SCS, the C coefficient for a hydrographic basin was calculated from different percentages of impermeable surface covering and previous physical and humidity characteristics for a specific soil type. So that, impermeable surfaces could be quantified and cartographic bases and surface covering these three periods were analyzed and treated digitally. In the digital photointerpretation technique the software Erdas Imagine $8.6^{\circledR}$ was used to obtain surface cover maps. As a final result, it was possible to determinate quantitative parameters for maximum retention of the soils (S) and runoff indexes (C). Besides, the interpolation under a GIS environment and coverage maps of the land surface with the soil map were used to build a map for multitemporal analysis of the runoff coefficients.
\end{abstract}

Keywords: runoff coefficients, impermeable surfaces, mapping, urbanization, Atuba River 


\section{Introdução}

Com o acelerado processo de urbanização verificado nas principais cidades brasileiras e suas regiões metropolitanas, as redes hidrográficas têm sofrido consideráveis modificações em seus cursos naturais, comprometendo, suas características originais e funcionais. Essas modificações são ocasionadas principalmente por obras de engenharia que vem impermeabilizado uma grande parcela das superfícies das bacias de drenagem por meio de edificações, pavimentações, calçamento, aterros e canalização dos cursos de água.

Para GENZ e TUCCI (1995) o recobrimento da superfície do terreno por obras de engenharia implica em uma maior quantidade e velocidade do escoamento superficial em um tempo menor, resultando no aumento da vazão de cheia, redução do tempo de concentração e diminuição da vazão de base, o que acarreta no aumento das inundações. Surge assim, a necessidade de estudos mais detalhados que visem compreender a variação do regime hidrológico causado pelo processo de adensamento urbano em bacias hidrográficas.

Uma das abordagens mais utilizadas em hidrologia para o estudo da dinâmica fluvial consiste na aplicação de modelos hidrológicos, que levam em consideração o percentual de áreas impermeabilizadas pelo processo de urbanização. No entanto, a aplicação desses modelos, somente tem um sentido quando a variabilidade espacial e temporal dos processos hidrológicos é considerada. Não se pode esquecer que uma das maiores limitações do uso desses modelos, tem sido a dificuldade na representação da distribuição espacial e temporal da capacidade de infiltração dos solos e dos índices de coeficiente de escoamento superficial, em bacia de médio e grande porte, devido à grande diversidade e distribuição heterogenia dos grupos pedológicos e das coberturas superficiais constituintes das mesmas.

Dentro desse contexto, o presente estudo teve por objetivo principal a aplicação do método de do Soil Conservation Service (SCS), juntamente com a utilização de técnicas de tratamento de dados em ambiente SIG. A aplicação dessas técnicas buscou avaliar a variação temporal e espacial do coeficiente de escoamento superficial (runoff), através da quantificação da impermeabilização do solo, ao longo do processo de adensamento urbano na bacia hidrográfica do rio Atuba em três períodos distintos:

I) início da década de 60, ano de 1962, quando a urbanização ocupava apenas $0,57 \%$ da área total da bacia, estando esta quase que em seu estado natural;

II) ano de 1980, início do processo de urbanização e;

III) ano 2000, período, em que se observa um acelerado aumento das regiões urbanas com a intensificação da impermeabilização do solo.

Dados fornecidos pela SEPL e PROSAM (1996), mostram que a bacia hidrográfica do rio Atuba é a segunda bacia mais urbanizada de Curitiba e suas imediações. Sendo selecionada como área de estudo, devido aos diversos fatores que a caracterizam tais como: elevado percentual de urbanização, registros de inundações em seu interior além da existência de um acervo de fotografias aéreas, que permitiu realizar a análise da densificação urbana, ao longo de um período de quarenta anos.

O método do SCS calcula o coeficiente C, ou seja, o coeficiente de escoamento superficial direto a partir das características da cobertura superficial do terreno e das características físicas e umidade antecedente, dos diferentes tipos de solos encontrados em uma bacia hidrográfica. Para avaliar as mudanças da dinâmica hidrológica, adotou-se a perspectiva de análise multitemporal, preocupando-se com as alterações decorrentes da atuação do homem sobre o ambiente hídrico, modificado pelas construções e obras de engenharia que impermeabilizam o solo.

\section{Bacia do rio Atuba}

A bacia hidrográfica do rio Atuba, com uma área de $127,43 \mathrm{~km}^{2}$, encontra-se no Primeiro Planalto Paranaense entre as coordenadas de $25 \circ$ 17' $00^{\prime \prime}$ e 25o $30^{\prime} 00^{\prime \prime}$ de latitudes sul e 49o 17' 00" e 49 10' 00" de longitudes oeste (Figura 01).

Suas nascentes situam-se no município de Colombo na região Serrana do Açungui, onde predominam áreas cobertas por florestas de vegetação densa ou campos com áreas verdes. O seu médio e baixo curso, com trechos canalizados e retificados, cortam as áreas intensamente urbanizadas da região de Curitiba, podendo ser observadas também, áreas com ocupações irregulares sobre as planícies de inundações, localizadas nas proximidades de sua confluência com o rio Iguaçu.

A geologia local é formada por rochas metamórficas de baixo grau do Proterozóico Superior e, de médio a alto grau do Proterozóico Inferior correspondente respectivamente a mármores, filitos, quartzitos e migmatitos-gnasseis, cortadas por diques de rochas básicas intrusivas de idade Mesozóica. Na área, são verificados também depósitos recentes ao longo das margens do rio principal, constituídos pelos terrenos aluvionais e culuvionaes do Terciário-Quaternário. De acordo com a sua distribuição litológica, a área em estudo pode ser dividida em quatro unidades geologicamente distintas: Grupo Açungui, Complexos Atuba, Formação Guabirotuba e depósitos colúvio-aluvionares do Holoceno (SALAMUNI, 1998).

Quanto aos aspectos geomorfológicos, a bacia do rio Atuba pode ser dividida em quatro unidades distintas: I) Sistema de Planícies Aluvionais, II) Sistema de Colinas Unidades de Topos Alongados, III) Sistema de Colinas Unidades de Topos Planos e, IV) Sistema de Morros.

O Sistema de Planícies Aluvionais possui um relevo praticamente plano a suave ondulado, com baixas declividades, menores que $10 \%$, onde sobressaem colinas suavemente onduladas. Possui depósitos sedimentares pouco entalhados e terrenos sujeitos a alagamento. 


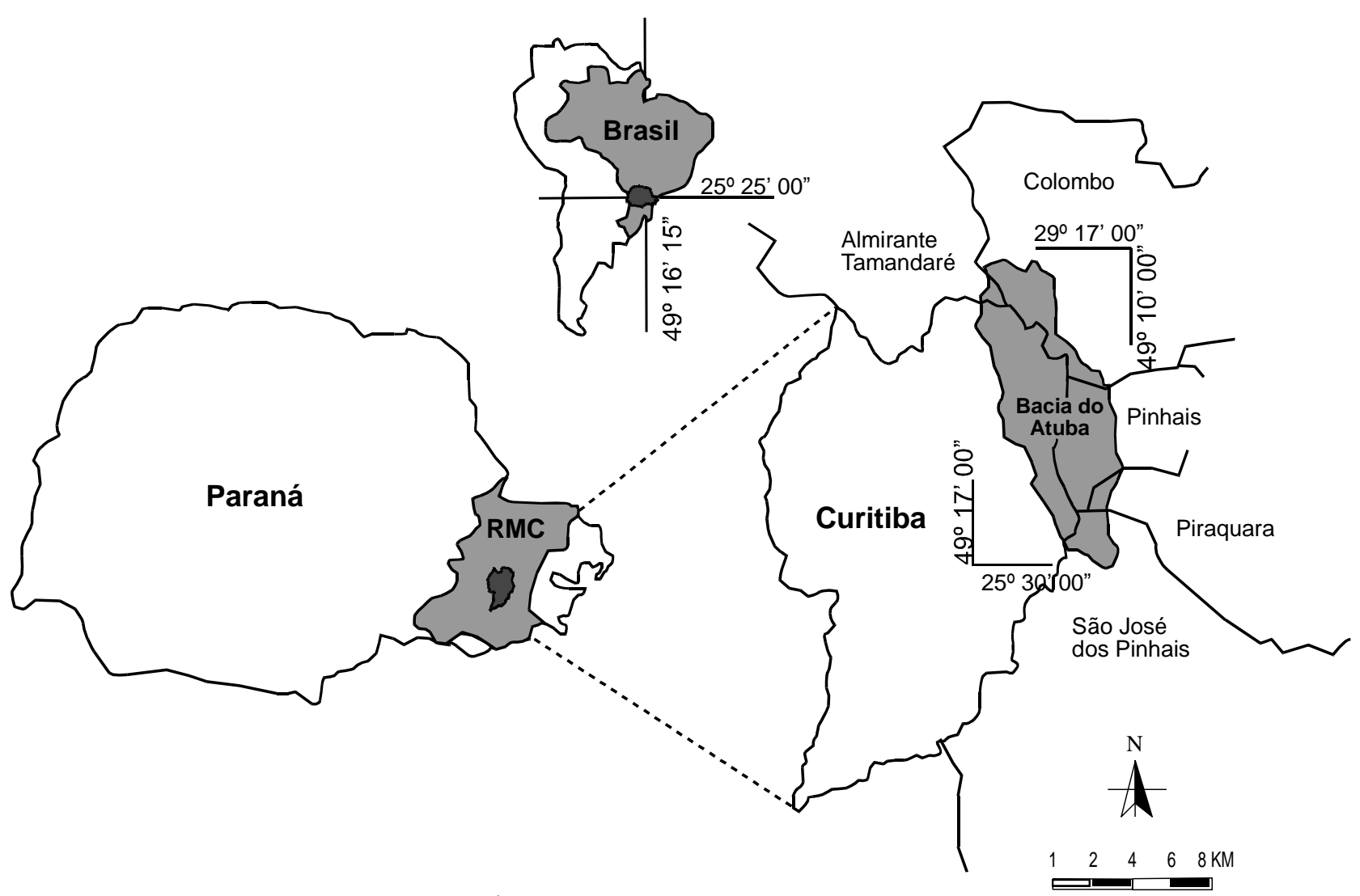

Figura 1 - Localização da Área em Estudo. Location of the studied area in the Paraná State.

O padrão de drenagem é paralelo com baixa densidade fluvial e fraca assimetria entre os seus canais de drenagem.

O Sistema de Colinas com unidades de topos alongados situa-se na parte central da área em estudo. Nesta unidade o processo de entalhamento e a dissecação da paisagem são lentos no desenvolvimento das formas de relevo. As vertentes possuem declividades moderadas de $10 \%$ a $20 \%$. No domínio da Formação Guabirotuba e Complexos Atuba a rede de drenagem é geralmente paralela a sub-dendrítica, com densidade média.

O Sistema de Colinas com unidades de topos planos aparece na porção centro-norte da bacia, com um relevo em forma de colinas bem arredondadas, tipo "meia laranja". Suas vertentes são suaves, côncavas em geral, com entalhamento e dissecação pouco profundos e declividade média de $20 \%$ a $30 \%$. Esta unidade é a que apresenta maior densidade fluvial, com padrão de drenagem sub-dendrítico e sub-retangular.

O Sistema de Morros corresponde à região do Grupo Açungui. Aparece no extremo norte da área da bacia, na região das nascentes do rio Atuba. O relevo desta unidade é formado por morros de cristas estreitas e alongadas. O padrão de drenagem que predomina é moderadamente retangular a treliça, estando, geralmente, adaptado às estruturas locais.

Os latossolos são predominantes na área da bacia, com perfis profundos, argilosos, bem porosos e drenados. Localizam-se principalmente nas regiões das declividades menos acentuadas, onde os depósitos das encostas são mais espessos. Nas áreas das maiores declividades ocorrem os cambissolos, que também são solos bem porosos e drenados, porém, com perfis de menor profundidade.

Ao longo das margens do rio principal e junto à sua foz, sobre os terrenos de planícies onde a circulação da água é baixa, ocorrem solos hidromórficos e orgânicos. Estes dois tipos de solos são mal ou muito mal drenados, geralmente, encharcados, devido à grande influência do lençol freático à superfície ou próxima dela.

\section{Método do Soil Conservation Service (SCS)}

Desenvolvido pelo Serviço de Conservação do Solo do Departamento de Agricultura dos Estados Unidos da América, o método do SCS é fundamentado em um parâmetro que busca descrever o tipo de uso do solo e a condição da superfície do terreno, em relação ao potencial de gerar escoamento superficial. Este parâmetro é representado pela sigla CN ('curve number' ou 'complex number'), tendo tradução em português de "número de escoamento" (OSTA, 1997).

Ainda conforme o autor, o valor de $\mathrm{CN}$ é compreendido entre zero e 100, sendo zero a representação de uma bacia de condutividade hidráulica infinita e 100 o valor correspondente a uma bacia totalmente impermeável.

A partir de dados de precipitação total e de precipitação efetiva em diversas bacias hidrográficas, o SCS estipulou valores de $\mathrm{CN}$ para vários tipos de solo, utilização superficial do terreno e condições de umidade antecedente 
do solo, tanto para áreas rurais como para os ambientes urbanos a suburbano (CHOW et al., 1988).

Como é provável que as bacias apresentem regiões com valores de $\mathrm{CN}$ distintos, o valor global pode ser calculado pela ponderação dos diversos valores parciais de $\mathrm{CN}$, feita em função das áreas, que cada um corresponde (OSTA, 1997).

De acordo com o manual de Fundamentos do modelo IPHS1 (2004) e CHOW et al. (1988), o algoritmo do SCS está baseado na proporção:

$\frac{(P-C)}{S}=\frac{C}{P} \quad$ (equação -01$)$

onde:

$\mathrm{P}=$ precipitação acumulada, ou seja, a precipitação total de um evento considerado $(\mathrm{mm})$;

$\mathrm{C}=$ coeficiente de escoamento superficial direto (coeficiente $\mathrm{C}$ );

$\mathrm{S}=$ coeficiente de armazenamento superficial, por infiltração, que está relacionada com os parâmetros que caracterizam a superfície (CN), dado em ( $\mathrm{mm})$.

O método considera uma perda inicial de água, igual à quantidade de precipitação que não produz escoamento no início da chuva de tormenta. Introduzindo a perda inicial ( ) da precipitação acumulada $(P)$ na equação anterior e isolando (C) obtêm-se:

$$
\left.C=\frac{(P-I a)^{2}}{(P-0,8 S)} \quad \text { (equação }-02\right)
$$

No método do SCS o valor da perda inicial $(I a)$, é considerado como $20 \%$ das perdas potenciais máximas, sendo:

$$
I a=0,2 \times S \quad \text { (equação }-03)
$$

Introduzindo a equação 03 em 02, obtêm-se as seguintes relações:

$$
\mathrm{C}=0 \text { para } \mathrm{P}<I a \text { e, } C=\left[\frac{(P-0,2 . S)^{2}}{(P+0,8 . S)}\right] \cdot \frac{1}{P} \text { para } \mathrm{P}>I a
$$

(equação - 04)

Para determinar a capacidade máxima de infiltração da camada superficial do solo (valor de S), o método do SCS relaciona esse parâmetro com o fator de $\mathrm{CN}$ pela seguinte expressão:

$$
\left.S=\frac{25400}{C N}-254 \quad \text { (equação }-05\right)
$$

A equação retrata as condições de cobertura superficial do terreno e do solo, variando desde superfície muito impermeável até superfície completamente permeável. Os valores de $\mathrm{CN}$ dependem das características físicas do solo, umidade antecedente do solo e da cobertura superficial do terreno.

Segundo TUCCl et al. (1995), a aplicação do método do SCS consiste nas seguintes etapas:

a) determinação do grupo hidrológico do solo;

b) escolha das condições de saturação do solo;

c) determinação de valores de CN para a condição de umidade do solo desejada e;

d) a determinação do escoamento superficial pela equação 04.

No método do SCS são considerados quatro grupos hidrológicos de solos e três condições de umidade antecedente, descritas a seguir:

- Grupo A: solos arenosos com baixo teor de argila total, inferior a 8\%, não havendo rocha nem camada argilosa, e nem mesmo densificadas até a profundidade de $1,5 \mathrm{~m}$. 0 teor de humos é muito baixo, não atingindo $1 \%$.

- Grupo B: solos arenosos menos profundos que os do Grupo A e com maior teor de argila total, porem, ainda inferior a $15 \%$. No caso de terras roxas, esse limite pode subir a $20 \%$ graças à maior porosidade. Os dois teores de humos podem subir, respectivamente, a 1,2 e 1,5\%. Neste grupo de solo não pode haver pedras e nem camadas argilosas até $1,5 \mathrm{~m}$, mas são, quase sempre, presentes camadas mais densificada que a camada superficial.

- Grupo C: solos argilosos com teor total de argila de $20 \%$ a $30 \%$, mas sem camadas argilosas impermeáveis ou contendo pedras até profundidade de $1,2 \mathrm{~m}$. No caso de terras roxas, esses dois limites máximos podem ser de $40 \%$ e $1,5 \mathrm{~m}$. Nota-se a cerca de $60 \mathrm{~cm}$ de profundidade, camada mais densificada que no Grupo B, mas ainda longe das condições de impermeabilidade.

- Grupo D: constituído por solos argilosos, com 30\% a $40 \%$ de argila total, com camada densificada a uns $50 \mathrm{~cm}$ de profundidade e quase impermeável. Ou solos arenosos como o do Grupo B, mas com camada de argila quase impermeável, ou horizonte de seixos rolados.

- Condição de umidade antecedente I - solos secos: as chuvas, nos últimos cinco dias, não ultrapassaram $15 \mathrm{~mm}$;

- Condição de umidade antecedente II - situação média na época das cheias: as chuvas, nos últimos cinco dias, totalizaram de 15 a $40 \mathrm{~mm}$;

Condição de umidade antecedente III - solo úmido (próximo da saturação): as chuvas, nos últimos cinco dias, foram superiores a $40 \mathrm{~mm}$. Os últimos cinco dias considerados no método do SCS são os cinco dias antecedentes ao dia da precipitação máxima analisada, em uma área a ser estudada.

\section{Procedimentos para aplicação do método do SCS}

No decorrer do trabalho foi necessário realizar o levantamento e o mapeamento de dados referentes aos tipos de solos e cobertura superficial do terreno, uma vez que o método de SCS utiliza-se da técnica de quantificação de áreas impermeáveis e da representação das 
características superficiais do terreno, para avaliar os impactos da urbanização sobre o sistema hídrico, em bacias hidrográficas urbanas a suburbana.

Para a confecção dos mapas de cobertura superficial do terreno foram interpretadas fotografias aéreas de diferentes datas de aquisição, utilizando a técnica de fotointerpretação digital trabalhada no software Erdas Imagine versão 8.6.

A referida técnica divide-se em três fases: fase de orientação das fotografias aéreas, subdividida em orientação interna e orientação externa; fase de restituição dos elementos observados nas fotografias aéreas e fase de controle de campo dos elementos mapeados.

$\mathrm{Na}$ fase de orientação interna foram atribuídos os parâmetros geodésicos de georreferenciamento como tipo da projeção, esferóide, datum, fator de escala do meridiano central, longitude do meridiano central e latitude de origem da projeção. Na fase de orientação externa, as fotografias aéreas foram georreferenciadas através da colocação de GCPs (ground control points) pontos de controle terrestre sobre as fotografias aéreas, tendo como base de referimento, cartas topográficas da região, em formato digital e registradas.

Durante a fase de restituição dos elementos observados nas fotografias aéreas inicialmente foram traçadas as estradas e a rede de drenagem, para serem utilizadas como pondo de ajuste. Após, foram estipuladas as classes temáticas para cada cobertura superficial do terreno, conforme os diferentes padrões de aglomerados urbanos e o tipo de uso e ocupação do solo, que serviram para determinar as áreas permeáveis e impermeáveis da bacia do rio Atuba (Tabela 01). Os diferentes padrões de aglomerados urbanos foram identificados por meio do adensamento das edificações, observando sempre o percentual da impermeabilização e dos espaços livres existentes entre as construções

Estipulada as classes temáticas de cobertura superficial do terreno foram, identificados e delimitados sobre as fotografias aéreas os polígonos que contornam cada classe. Cada polígono gerado foi classificado de acordo com a sua temática observada nas fotografias aéreas dos anos de 1962, 1980 e 2000. Como resultado desta etapa do trabalho, teve-se a confecção das cartas de cobertura superficial do terreno da bacia hidrográfica do rio Atuba, para a realização da análise multitemporal (Figura 02).

Os dados referentes às características físicas do solo foram extraídos do mapa e do Boletim Técnico de Levantamento de Reconhecimento dos Solos do Estado do Paraná, confeccionado a partir do convênio EMBRAPA e IAPAR (1984).

Como classes mapeadas na área de estudo, apresentam-se os: latossolo vermelho amarelo (LVa); cambissolos álicos (Ca); terra roxa estruturada distrófica (TRd), solos orgânicos álicos (HOa) e solos hidromórficos gleyzados (HG), associados ou não (Figura 03).

A partir do mapeamento dos solos da bacia do rio Atuba e dos dados de suas características físicas, determinaram-se os grupos hidrológicos de solos para a bacia hidrográfica em estudo, indicados na Tabela 02.

Para a aplicação do método foi necessário também o levantamento de dados pluviométricos, que foram utilizados na calibragem do modelo e no estudo propriamente dito. Como dados de entrada, selecionou-se somente a maior chuva causadora de tormenta severa, verificada em uma série histórica que se estende entre o período de 1989 a 2004. Posteriormente, a esta tormenta, foi somada a precipitação total dos cinco dias anteriores ao dia da maior precipitação, para a análise das condições de umidade antecedentes do solo conforme propõe o método do SCS.

Como principal tormenta severa somada às precipitações dos cinco dias anteriores, tem-se a de chuva de janeiro de 1995 com 176,71mm. Este valor foi estimado a partir do cálculo da precipitação média, através do método do Polígono de Thiessen, aplicado com dados de estações pluviométricas circunvizinhas à área em estudo.

Em ambiente SIG foi criado um banco de dados contendo informações temáticas da cobertura superficial do terreno (dos anos de 1962, 1980 e 2000) e dos tipos de solo, estruturado, através de mapas e de dados alfanuméricos. Por fim, obtiveram-se os mapas de índices de escoamento superficial do terreno (Figura 04), a partir da interpolação das informações armazenadas no banco de dado do SIG, por meio da linguagem de programação espacial para geoprocessamento algébrico (LEGAL), disponível no software Spring.

Tabela 1 - Classes de cobertura superficial do terreno. Types of surface covering of the land.

\section{Classes Temáticas}

1- Edificação muito densa: partes centrais densamente construídas de uma cidade com cerca de $85 \%$ de impermeabilização.

2- Edificação não muito densa: zonas residênciais adjacentes ao centro, de menor densidade de habitação que as regiões centrais, com cerca de $65 \%$ de impermeabilização.

3- Edificações com superfícies livres: zonas residênciais com cerca de 38\% de impermeabilização.

4- Edificações com muitas superficies livres: zonas residênciais com construções esparsas com cerca de 30\% de impermeabilização.

5- Zonas industriais e comerciais: áreas industrias e barracão de comércios com cerca de $72 \%$ de impermeabilização.

6- Campo e áreas verdes: parques, jardins, campos de esportes, áreas cultivadas e áreas com gramados.

7- Zonas florestais e vegetação densa: área com vegetação de porte arboreo natural ou reflorestadas em boas condições.

8-Corpos d'água: lagos artificiais ou naturais. 


\section{Coberturas Superficial do Terreno da Bacia Hidrográfica do Rio Atuba}

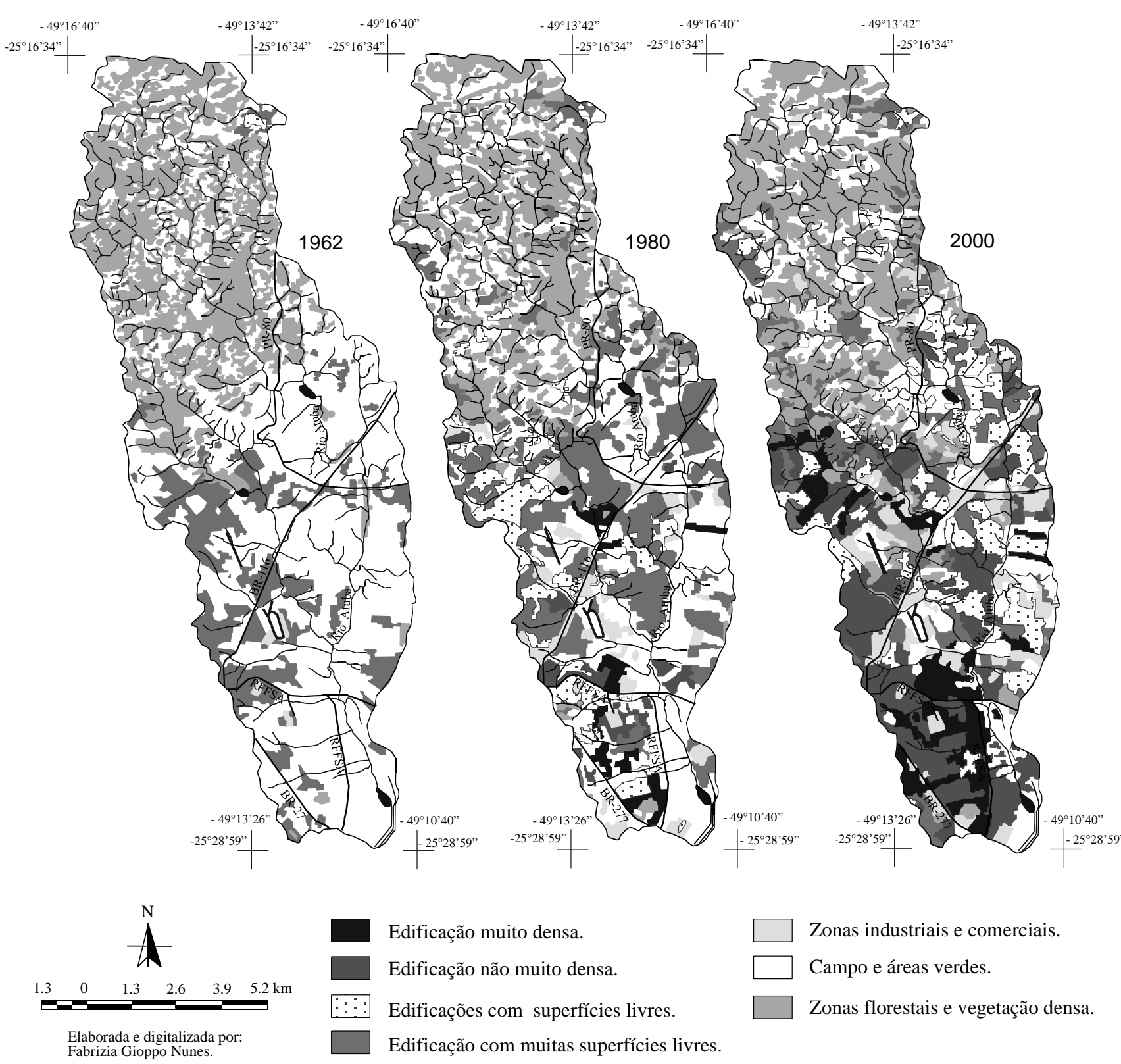

Figura 2 - Cartas da evolução da cobertura superficial do terreno na bacia hidrográfica do rio Atuba. Evolution map of the surface covering of the land for Atuba River hydrographic basin.

\section{Determinação dos valores de (CN)}

Os valores de $\mathrm{CN}$ foram estimados a partir da utilização do modulo cálculo do CN, para bacias urbanas e suburbanas, contido no modelo hidrológico-hidrodinâmico IPHS1 versão 2.1, elaborado pelo Instituto de Pesquisas Hidráulicas da UFRGS e Faculdade de Engenharia Agrícola UFPel. O modelo fornece o valor de $\mathrm{CN}$ para cada umidade antecedente dos solos, a partir da interpolação de características da cobertura superficial do terreno com cada grupo hidrológico de solos, considerado no método do SCS.

A Tabela 03 ilustra os valores de $\mathrm{CN}$ calculados para cada tipo de cobertura superficial do terreno, grupo hidrológico de solos e condições I, II e III de umidade antecedente na bacia hidrográfica do rio Atuba.

\section{Determinação dos valores do coeficiente de armazenamento (S)}

Por meio da equação 05 que estipula a capacidade máxima de infiltração da camada superficial do solo, foram calculados os valores do parâmetro $\mathrm{S}$ para cada tipo de cobertura superficial do terreno, grupo hidrológico de solos e condições de umidade antecedente, obtidos com base nos valores de $\mathrm{CN}$ tabelados. Os valores de $\mathrm{S}$ obtidos são apresentados na Tabela 04. 


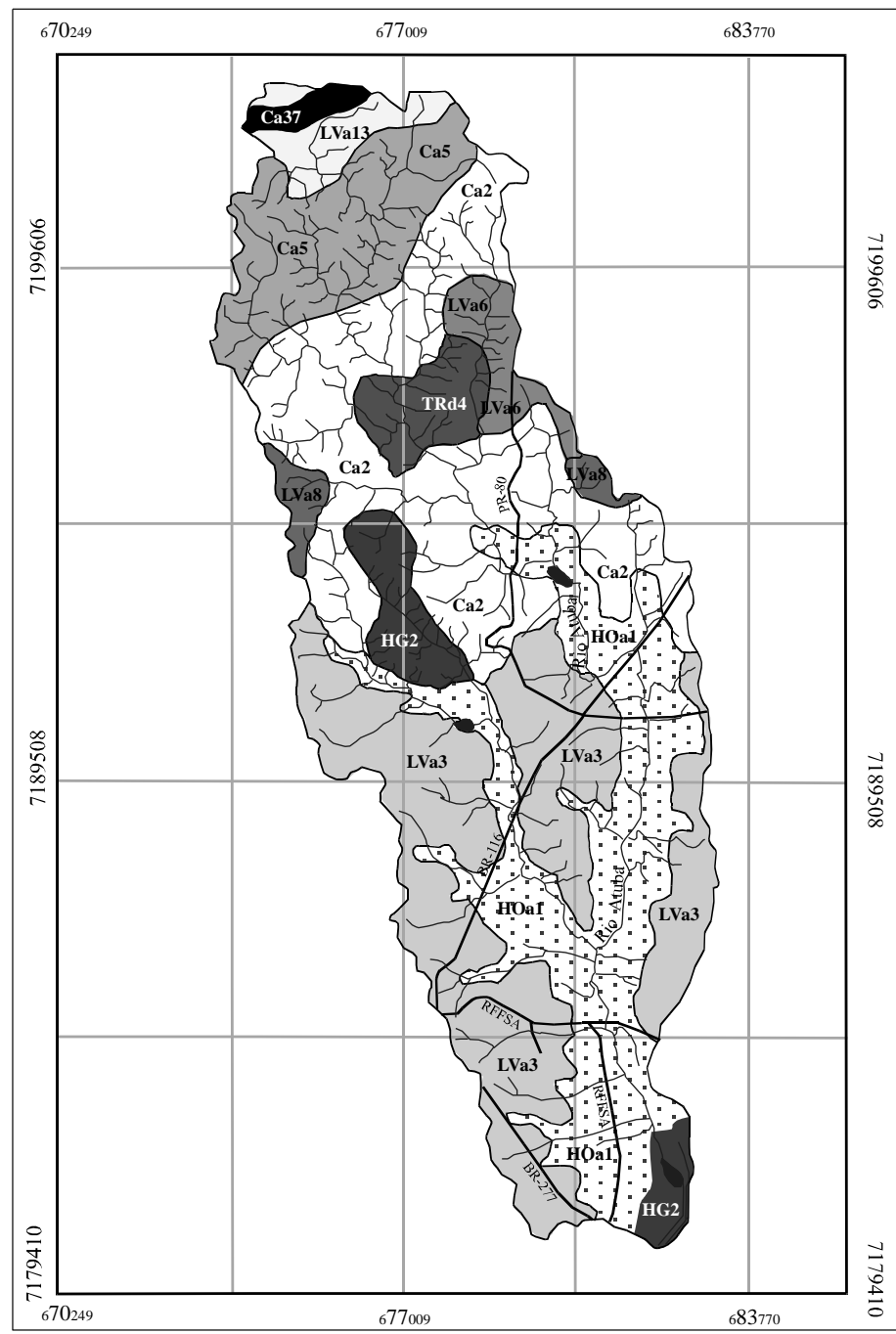

\section{Mapa de Solos da Bacia Hidrográfica do Rio Atuba}

$\square$ LVa3 - Latossolo vermelho amarelo álico A proeminente textura argilosa fase campo subtropical relevo suave ondulado.

LVa6 - Latossolo vermelho amarelo álico pouco profundo A proeminente textura argilosa fase floresta subtropical perenifólia relevo suave ondulado e ondulado.

LVa8 - Latossolo vermelho amarelo álico pouco profundo A proeminente textura argilosa fase campo subtropical relevo suave ondulado.

LVa13 - Associação latossolo vermelho-amarelo álico relevo ondulado + cambissolo álico $\mathrm{Tb}$ relevo forte ondulado substrato filitos ambos A proeminente textura argilosa fase campo subtropical.

Ca2 - Cambissolo álico Tb A proeminente textura argilosa fase floresta subtropical perenifólia relevo ondulado substrato migmatitos.

Ca5 - Cambissolo álico Tb A proeminente textura argilosa fase floresta subtropical perenifólia relevo forte ondulado substrato filitos.

Ca37 - Associação cambissolo álico Tb relevo forte ondulado + Solos litólicos distróficos relevo montanhoso ambos A moderado textura argilosa fase campo subtropical substrato filitos.

TRd4 - Associação de terra roxa estruturada distrófica fase floresta subtropical perenifólia relevo ondulado + Latossolo roxo distrófico + Solos litólicos eutróficos todos A moderado textura argilosa.

HG2 - Solos hidromórficos gleyzados indiscriminados textura argilosa fase campo e floresta subtropical de várzea relevo plano.

HOa1 - Solos orgânicos álicos fase campo subtropical de várzea relevo plano.

If Rios

- Estradas/ Ferrovias

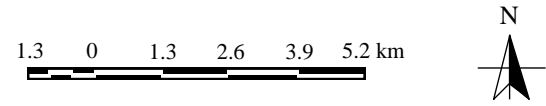

Fonte: Modificada da carta de Solos da EMBRAPA (1984)/ Levantamento e Reconhecimento dos Solos do Estado do Paraná

Organizada e digitalizada por Fabrizia Gioppo Nunes sob, orientação de Alberto Pio Fiori

Figura 3 - Mapa de solos da área de estudo. Soil map of the study area.

Tabela 2 - Grupos hidrológicos de solos da bacia hidrográfica do rio Atuba. Hidrological groups of soil for Atuba River hydrographic basin.

\begin{tabular}{|c|c|c|c|c|c|}
\hline Classes & Características & Unidades & Material de origem & $\begin{array}{c}\text { Área em km² } \\
\text { (na bacia) }\end{array}$ & $\begin{array}{c}\text { Grupos } \\
\text { hidrológicos } \\
\end{array}$ \\
\hline \multirow[t]{4}{*}{$\begin{array}{l}\text { LATOSSOLO VERMELHO } \\
\text { AMARELO }\end{array}$} & \multirow{4}{*}{$\begin{array}{l}\text { textura argilosa, } \\
\text { porosos, } \\
\text { bem drenado }\end{array}$} & LVa3 & $\begin{array}{l}\text { sedimentos argilosos, } \\
\text { arcósios e areias finas }\end{array}$ & $34,85 \mathrm{~km}^{2}$ & $\mathrm{C}$ \\
\hline & & LVa6 & rochas dos Complexos Atuba & $3,45 \mathrm{~km}^{2}$ & $\mathrm{C}$ \\
\hline & & LVa8 & rochas dos Complexos Atuba & $2,13 \mathrm{~km}^{2}$ & $\mathrm{C}$ \\
\hline & & LVa13 & rochas do Grupo Açungui & $3,40 \mathrm{~km}^{2}$ & $\mathrm{C}$ \\
\hline \multirow[t]{3}{*}{ CAMBISSOLOS ÁLICOS } & \multirow{3}{*}{$\begin{array}{l}\text { textura argilosa, } \\
\text { porosos, } \\
\text { moderado a bem } \\
\text { drenado }\end{array}$} & Ca2 & $\begin{array}{c}\text { rochas dos Complexos } \\
\text { Atuba }\end{array}$ & $30,64 \mathrm{~km}^{2}$ & $\mathrm{C}$ \\
\hline & & Ca5 & $\begin{array}{c}\text { transição ente rochas do } \\
\text { Grupo Açungui e dos } \\
\text { Complexos Atuba }\end{array}$ & $13,04 \mathrm{~km}^{2}$ & C \\
\hline & & Ca37 & rochas do Grupo Açungui & $1,25 \mathrm{Km}^{2}$ & C \\
\hline $\begin{array}{l}\text { TERRA ROXA } \\
\text { ESTRUTURADA } \\
\text { DISTRÓFICA } \\
\end{array}$ & $\begin{array}{l}\text { textura argilosa, } \\
\text { porosos, bem drenado }\end{array}$ & TRd4 & rochas dos Complexos Atuba & $4,53 \mathrm{~km}^{2}$ & C \\
\hline $\begin{array}{l}\text { SOLOS HIDROMÓRFICOS } \\
\text { GLEYZADOS }\end{array}$ & $\begin{array}{l}\text { textura argilosa, } \\
\text { camada densificada, } \\
\text { mal a muito mal } \\
\text { drenados }\end{array}$ & HG2 & $\begin{array}{l}\text { sedimentos aluvionais } \\
\text { não consolidados }\end{array}$ & $6,16 \mathrm{~km}^{2}$ & $\mathrm{D}$ \\
\hline SOLOS ORGÂNICOS ÁLICOS & mal drenados & HOa1 & $\begin{array}{c}\text { sedimentos coluvio aluviais } \\
\text { do Quaternário }\end{array}$ & $29,47 \mathrm{~km}^{2}$ & $\mathrm{D}$ \\
\hline
\end{tabular}




\section{Coeficientes de Escoamento Superficial da Bacia Hidrográfica do Rio Atuba}

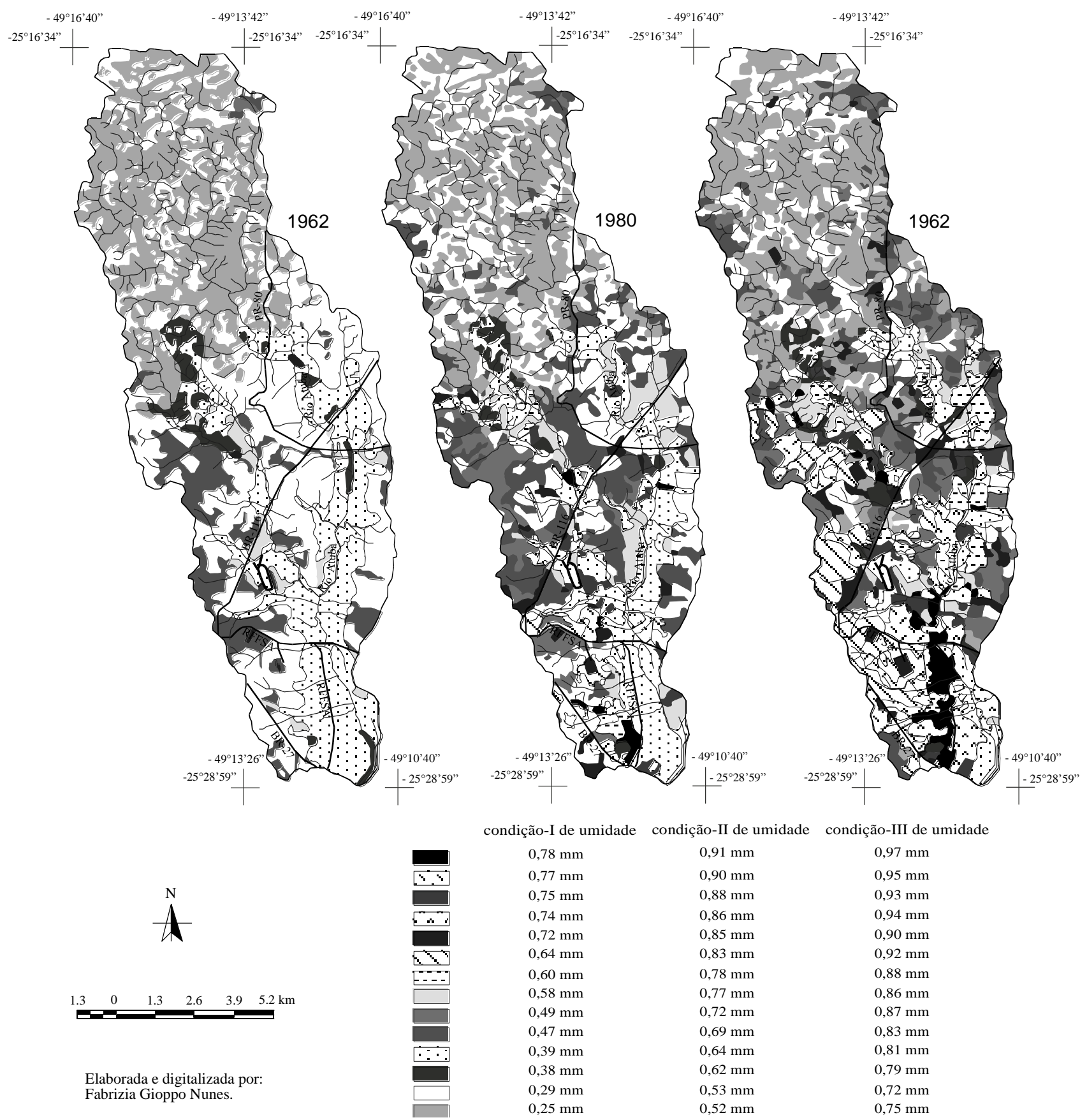

Figura 4 - Mapa dos valores de C runoff, calculados pelo emprego da equação 4. C (runoff) factor's map obtained through the equation number 4.

\section{Determinação da perda inicial da precipitação ( $I a$ )}

Tendo em vista que o valor da perda inicial da chuva é equivale a $20 \%$ da precipitação total, como considerado no método do SCS, calculou-se através da equação 03 os valores da perda inicial ( $I a$ ) para bacia do rio Atuba, de acordo com cada um dos grupos hidrológicos de solos identificados e umidade antecedente (Tabela 05).
8. Determinação dos valores do coeficiente de escoamento superficial (C)

Os valores do coeficiente de escoamento superficial direto (coeficiente $\mathrm{C}$ ) foram determinados com base na relação $\mathrm{C}=0$ para $\mathrm{P}<I a$ e na equação 04 para $\mathrm{P}>I a$. Como resultado da aplicação destas equações, é apresentada a Tabela 06, contendo os dados dos coeficientes de escoamento superficial calculados para a maior tormenta severa analisada e, somada aos cinco dias 
Tabela 3 - Valores de CN em função da cobertura superficial do terreno, do tipo hidrológico e condição de umidade do solo para a bacia hidrográfica do rio Atuba. The CN values for several (or different) superficial covering of the land, soil types and condition of antecedent humidity of the soil for Atuba river hydrographic basin.

\begin{tabular}{|c|c|c|c|c|c|c|}
\hline \multirow{3}{*}{ Tipo de Cobertura Superficial do Terreno } & \multicolumn{6}{|c|}{ Valor de CN } \\
\hline & \multicolumn{2}{|c|}{$\begin{array}{c}\text { condição-I de umidade } \\
\text { e grupo hidrológico } \\
\text { de solos }\end{array}$} & \multicolumn{2}{|c|}{$\begin{array}{c}\text { condição-II de umidade } \\
\text { e grupo hidrológico } \\
\text { de solos }\end{array}$} & \multicolumn{2}{|c|}{$\begin{array}{c}\text { condição-III de umidade } \\
\text { e grupo hidrológico } \\
\text { de solos }\end{array}$} \\
\hline & C & D & C & D & C & D \\
\hline $\begin{array}{l}\text { Edificação muito densa: em média } 85 \% \text { de áreas } \\
\text { impermeáveis. }\end{array}$ & 86,08 & 87,00 & 94,00 & 95,00 & 96,97 & 98,00 \\
\hline $\begin{array}{l}\text { Edificação não muito densa: em média 65\% de áreas } \\
\text { impermeáveis. }\end{array}$ & 78,00 & 84,25 & 90,00 & 92,00 & 96,00 & 94,91 \\
\hline $\begin{array}{l}\text { Edificações com superfícies livres: em média 38\% de } \\
\text { áreas impermeáveis. }\end{array}$ & 68,35 & 75,40 & 83,00 & 87,00 & 91,79 & 92,80 \\
\hline $\begin{array}{l}\text { Edificação com muitas superfícies livres: em média 30\% } \\
\text { de áreas impermeáveis. }\end{array}$ & 66,71 & 74,53 & 81,00 & 86,00 & 89,58 & 91,73 \\
\hline $\begin{array}{l}\text { Zonas industriais e comerciais: em média } 72 \% \text { de áreas } \\
\text { impermeáveis. }\end{array}$ & 83,34 & 85,17 & 91,00 & 93,00 & 94,00 & 95,94 \\
\hline Campo e áreas verdes. & 53,96 & 61,43 & 71,00 & 78,00 & 83,31 & 88,73 \\
\hline Zonas florestais e vegetação densa. & 51,00 & 60,64 & 70,00 & 77,00 & 85,00 & 87,59 \\
\hline
\end{tabular}

Tabela 4 - Valores de S dados em função da cobertura superficial do terreno, do tipo hidrológico e condição de umidade do solo para a bacia hidrografia do rio Atuba. The $S$ values for several (or different) superficial covering of the land, soil types and condition of antecedent humidity of the soil for Atuba river hydrographic basin.

\begin{tabular}{|c|c|c|c|c|c|c|}
\hline \multirow{3}{*}{ Tipo de Cobertura Superficial do Terreno } & \multicolumn{6}{|c|}{ Valores de "S" em (mm) } \\
\hline & \multicolumn{2}{|c|}{$\begin{array}{c}\text { condição-I de umidade } \\
\text { e grupo hidrológico } \\
\text { de solos. }\end{array}$} & \multicolumn{2}{|c|}{$\begin{array}{c}\text { condição-II de umidade } \\
\text { e grupo hidrológico } \\
\text { de solos. }\end{array}$} & \multicolumn{2}{|c|}{$\begin{array}{c}\text { condição-III de umidade } \\
\text { e grupo hidrológico } \\
\text { de solos. }\end{array}$} \\
\hline & $\mathbf{C}$ & D & C & D & $\mathbf{C}$ & D \\
\hline $\begin{array}{l}\text { Edificações muito densas: em média 85\% de áreas } \\
\text { impermeáveis. }\end{array}$ & 41,07 & 37,95 & 16,21 & 13,37 & 7,9 & 5,18 \\
\hline $\begin{array}{l}\text { Edificações não muito densas: em média } 65 \% \text { de áreas } \\
\text { impermeáveis. }\end{array}$ & 71,64 & 47,48 & 28,22 & 22,08 & 12,27 & 9,59 \\
\hline $\begin{array}{l}\text { Edificações com superfícies livres: em média 38\% de } \\
\text { áreas impermeáveis. }\end{array}$ & 117,61 & 82,87 & 52,02 & 37,95 & 22,72 & 19,70 \\
\hline $\begin{array}{l}\text { Edificações com muitas superfícies livres: em média } 30 \% \\
\text { de áreas impermeáveis. }\end{array}$ & 126,75 & 86,80 & 59,58 & 41,35 & 28,88 & 22,90 \\
\hline $\begin{array}{l}\text { Zonas industriais e comerciais: em média } 72 \% \text { de áreas } \\
\text { impermeáveis. }\end{array}$ & 50,77 & 44,22 & 25,12 & 19,12 & 16,21 & 10,75 \\
\hline Campo e áreas verdes. & 216,72 & 159,48 & 103,74 & 71,64 & 50,88 & 32,26 \\
\hline Zonas florestais e vegetação densa. & 244,04 & 164,65 & 108,86 & 75,87 & 44,82 & 35,98 \\
\hline
\end{tabular}

Tabela 5 - Valores de $I a(\mathrm{~mm})$ dados em função da cobertura superficial do terreno, do tipo hidrológico e condição de umidade do solo. The Ia values several (or different) superficial covering of the land, soil types and condition of antecedent humidity of the soil for Atuba river hydrographic basin.

\begin{tabular}{|c|c|c|c|c|c|c|}
\hline \multirow{3}{*}{ Tipo de Cobertura Superficial do Terreno } & \multicolumn{6}{|c|}{ Valores de la em (mm) } \\
\hline & \multicolumn{2}{|c|}{$\begin{array}{c}\text { condição-I de umidade } \\
\text { e grupo hidrológico } \\
\text { de solos. }\end{array}$} & \multicolumn{2}{|c|}{$\begin{array}{c}\text { condição-II de umidade } \\
\text { e grupo hidrológico } \\
\text { de solos. }\end{array}$} & \multicolumn{2}{|c|}{$\begin{array}{c}\text { condição-III de umidade } \\
\text { e grupo hidrológico } \\
\text { de solos. }\end{array}$} \\
\hline & C & D & C & D & C & D \\
\hline $\begin{array}{l}\text { Edificações muito densas: em média } 85 \% \text { de áreas } \\
\text { impermeáveis. }\end{array}$ & 8,21 & 7,59 & 3,24 & 2,6 & 1,6 & 1,03 \\
\hline $\begin{array}{l}\text { Edificações não muito densas: em média } 65 \% \text { de áreas } \\
\text { impermeáveis. }\end{array}$ & 14,32 & 9,49 & 5,64 & 4,4 & 2,45 & 1,92 \\
\hline $\begin{array}{l}\text { Edificações com superfícies livres: em média 38\% de } \\
\text { áreas impermeáveis. }\end{array}$ & 23,52 & 16,57 & 10,40 & 7,6 & 4,54 & 3,94 \\
\hline $\begin{array}{l}\text { Edificações com muitas superfícies livres: em média 30\% } \\
\text { de áreas impermeáveis. }\end{array}$ & 25,35 & 17,36 & 11,91 & 8,27 & 5,77 & 4,58 \\
\hline $\begin{array}{l}\text { Zonas industriais e comerciais: em média } 72 \% \text { de áreas } \\
\text { impermeáveis. }\end{array}$ & 10,15 & 8,84 & 5,02 & 3,82 & 3,24 & 2,15 \\
\hline Campo e áreas verdes. & 43,34 & 31,89 & 20,74 & 14,33 & 10,17 & 6,45 \\
\hline
\end{tabular}


Tabela 6 - Valores de C dados em função da cobertura superficial do terreno, do tipo hidrológico e condição de umidade antecedente do solo para precipitação severa $(176,96 \mathrm{~mm})$ na bacia do rio Atuba. The C values for several (or different) superficial covering of the land, soil types and condition of antecedent humidity of the soil for severe precipitations in Atuba river hydrographic basin.

\begin{tabular}{|c|c|c|c|c|c|c|}
\hline \multirow{3}{*}{ Tipo de Cobertura Superficial do Terreno } & \multicolumn{6}{|c|}{ Valores de "C" } \\
\hline & \multicolumn{2}{|c|}{$\begin{array}{c}\text { condição-I de umidade } \\
\text { e grupo hidrológico } \\
\text { de solos. }\end{array}$} & \multicolumn{2}{|c|}{$\begin{array}{c}\text { condição-II de umidade } \\
\text { e grupo hidrológico } \\
\text { de solos. }\end{array}$} & \multicolumn{2}{|c|}{$\begin{array}{c}\text { condição-III de umidade } \\
\text { e grupo hidrológico } \\
\text { de solos. }\end{array}$} \\
\hline & C & D & C & D & C & D \\
\hline $\begin{array}{l}\text { Edificações muito densas: em média } 85 \% \text { de áreas } \\
\text { impermeáveis. }\end{array}$ & 0,77 & 0,78 & 0,90 & 0,91 & 0,95 & 0,97 \\
\hline $\begin{array}{l}\text { Edificações não muito densas: em média } 65 \% \text { de áreas } \\
\text { impermeáveis. }\end{array}$ & 0,64 & 0,74 & 0,83 & 0,86 & 0,92 & 0,94 \\
\hline $\begin{array}{l}\text { Edificações com superfícies livres: em média 38\% de } \\
\text { áreas impermeáveis. }\end{array}$ & 0,49 & 0,60 & 0,72 & 0,78 & 0,86 & 0,88 \\
\hline $\begin{array}{l}\text { Edificação com muitas superfícies livres: em média 30\% } \\
\text { de áreas impermeáveis. }\end{array}$ & 0,47 & 0,58 & 0,69 & 0,77 & 0,83 & 0,87 \\
\hline $\begin{array}{l}\text { Zonas industriais e comerciais: em média } 72 \% \text { de áreas } \\
\text { impermeáveis. }\end{array}$ & 0,72 & 0,75 & 0,85 & 0,88 & 0,90 & 0,93 \\
\hline Campo e áreas verdes. & 0,29 & 0,39 & 0,53 & 0,64 & 0,72 & 0,81 \\
\hline Zonas florestais e vegetação densa. & 0,25 & 0,38 & 0,52 & 0,62 & 0,75 & 0,79 \\
\hline
\end{tabular}

de precipitações antecedentes a elas. Sendo assim, os valores de $\mathrm{C}$ foram calculados para a chuva acumulada de $176,96 \mathrm{~mm}$, por ser esta a maior tormenta severa observada nos registros pluviométricos analisados.

Como a bacia apresenta regiões com valores de coeficiente de escoamento superficial distintos, em função dos tipos de cobertura superficial do terreno e dos grupos hidrológicos de solos, esses valores foram mapeados em ambiente SIG para possibilitar o cálculo da área que cada valor de $\mathrm{C}$ corresponde dentro do perímetro da bacia (Figura 04). As áreas totais de cada tipo de cobertura superficial do terreno combinadas aos grupos hidrológicos de solos, na determinação dos valores de C, podem ser verificadas na Tabela 07.

Tabela 7 - Relação entre o coeficiente $\mathrm{C}$ e o percentual de áreas ocupadas na bacia hidrográfica do rio Atuba. Relationship between the coefficient $C$ and the percentage of occupied areas in the river basin Atuba.

\begin{tabular}{|c|c|c|c|c|c|c|}
\hline \multirow[b]{2}{*}{ Tipo de Cobertura Superficial do Terreno } & \multicolumn{3}{|c|}{ Valor de "C" } & \multicolumn{3}{|c|}{ Área em $\left(\mathrm{km}^{2}\right) /$ Ano } \\
\hline & $\begin{array}{l}\text { condição-I de } \\
\text { umidade. }\end{array}$ & $\begin{array}{l}\text { condição-II de } \\
\text { umidade. }\end{array}$ & $\begin{array}{l}\text { condição-III de } \\
\text { umidade. }\end{array}$ & 1962 & 1980 & 2000 \\
\hline $\begin{array}{l}\text { Edificações muito densas: em média } 85 \% \text { de áreas } \\
\text { impermeáveis + solos do tipo D. }\end{array}$ & 0,78 & 0,91 & 0,97 & 0,05 & 1,26 & 3,88 \\
\hline $\begin{array}{l}\text { Edificações muito densas: em média } 85 \% \text { de áreas } \\
\text { impermeáveis + solos do tipo C. }\end{array}$ & 0,77 & 0,90 & 0,95 & 0,11 & 1,80 & 5,55 \\
\hline $\begin{array}{l}\text { Zonas industriais e comerciais: em média } 72 \% \text { de } \\
\text { áreas impermeáveis + solos do tipo D. }\end{array}$ & 0,75 & 0,88 & 0,93 & 0,12 & 2,35 & 3,26 \\
\hline $\begin{array}{l}\text { Edificações não muito densas: em média 65\% de } \\
\text { áreas impermeáveis + solos do tipo D. }\end{array}$ & 0,74 & 0,86 & 0,94 & 0,00 & 1,03 & 7,46 \\
\hline $\begin{array}{l}\text { Zonas industriais e comerciais: em média } 72 \% \text { de } \\
\text { áreas impermeáveis + solos do tipo C. }\end{array}$ & 0,72 & 0,85 & 0,90 & 0,14 & 2,36 & 4,88 \\
\hline $\begin{array}{l}\text { Edificações não muito densas: em média } 65 \% \text { de } \\
\text { áreas impermeáveis + solos do tipo C. }\end{array}$ & 0,64 & 0,83 & 0,92 & 0,00 & 1,95 & 11,27 \\
\hline $\begin{array}{l}\text { Edificações com superfícies livres: em média 38\% } \\
\text { de áreas impermeáveis + solos do tipo D. }\end{array}$ & 0,60 & 0,78 & 0,88 & 0,00 & 2,08 & 5,33 \\
\hline $\begin{array}{l}\text { Edificações com muitas superfícies livres: em } \\
\text { média 30\% de áreas impermeáveis + solos do tipo } \\
\text { D. }\end{array}$ & 0,58 & 0,77 & 0,87 & 3,61 & 7,64 & 3,78 \\
\hline $\begin{array}{l}\text { Edificações com superfícies livres: em média 38\% } \\
\text { de áreas impermeáveis + solos do tipo C. }\end{array}$ & 0,49 & 0,72 & 0,86 & 0,27 & 6,75 & 12,38 \\
\hline $\begin{array}{l}\text { Edificações com muitas superfícies livres: em } \\
\text { média 30\% de áreas impermeáveis + solos do tipo } \\
\text { C. }\end{array}$ & 0,47 & 0,69 & 0,83 & 12,00 & 19,45 & 11,41 \\
\hline Campo e áreas verdes + solos do tipo D. & 0,39 & 0,64 & 0,81 & 28,40 & 19,00 & 8,13 \\
\hline $\begin{array}{l}\text { Zonas florestais e vegetação densa + solos do tipo } \\
\text { D. }\end{array}$ & 0,38 & 0,62 & 0,79 & 3,27 & 1,71 & 3,19 \\
\hline Campo e áreas verdes + solos do tipo C. & 0,29 & 0,53 & 0,72 & 47,91 & 34,24 & 19,23 \\
\hline $\begin{array}{l}\text { Zonas florestais e vegetação densa + solos do tipo } \\
\text { C. }\end{array}$ & 0,25 & 0,52 & 0,75 & 31,55 & 25,5 & 27,76 \\
\hline Corpos d'água. & $\begin{array}{c}---- \\
-4\end{array}$ & $\begin{array}{c}---- \\
-\end{array}$ & $\begin{array}{c}---- \\
-\end{array}$ & 0,06 & 0,06 & 0,14 \\
\hline
\end{tabular}


Para uma melhor análise da evolução do coeficiente de escoamento superficial ao longo dos três períodos estudados, o valor de $\mathrm{C}$ de cada ano, foi obtido pela média ponderada dos diversos valores de $\mathrm{C}$ correspondentes às suas áreas homogêneas. Assim, os valores de $\mathrm{C}$ foram determinados pelo produto da participação percentual de cada grupo hidrológico de solos pelos respectivos valores do produto do percentual da área de cada tipo de cobertura superficial do terreno.

Como resultado final os valores médio de $\mathrm{C}$ calculados foram: 0,33 para 1962; 0,39 para 1980 e 0,47 para 2000 em condição de umidade antecedente I, ou seja, em solos secos. Em condição de umidade antecedente II, situação média, os valores foram: 0,58 para 1962; 0,62 para 1980 e 0,68 para 2000. Nos solos próximos da saturação, em condições III de umidade antecedente, os valores médios de $C$ aumentaram de: 0,76 em 1962 para 0,80 em 1980 e para 0,83 em 2000.

\section{Discussão}

A evolução urbana, responsável pelas mudanças na cobertura superficial da bacia do rio Atuba e, conseqüente impermeabilização de seus solos, pode ser observada através dos três anos analisados (Figura 05). Tendo como referência o ano de 1962 , mais de $87 \%$ da superfície $(110,91 \mathrm{~km} 2)$ era ocupada pela classe de zonas florestais e vegetação densa e pela classe de campo e áreas verdes. Em 1980 estas classes mostraram uma grande diminuição, passando a ocupar $63,35 \%(80,79 \mathrm{~km} 2)$ da área em estudo.

Em 2000, a classe de zonas florestais e vegetação densa mostram uma ligeira recuperação, passando de 21,12 \% $(27,050 \mathrm{~km} 2)$ para $24,12 \%(30,747 \mathrm{~km} 2)$ da área. Já os campos e áreas verdes continuaram a diminuir, cedendo espaços as áreas edificadas.

Nota-se que estas duas classes de vegetação apareciam bem distribuídas por toda a bacia nos anos de 1962 e 1980, restringe-se, no mapa de 2000, quase que na sua totalidade às regiões do alto e médio curso. Isto evidência que o processo de urbanização na bacia do rio Atuba, como na maioria das bacias hidrográficas brasileiras, vem ocorrendo na direção de jusante para montante.

$\mathrm{Na}$ comparação dos mapas de cobertura superficial do terreno (Figuras 02) com o mapa de solos (Figura 03), visualiza-se que as maiores concentrações urbanas localizam-se do médio ao baixo curso da bacia, sobre as áreas de latossolos e solos hidromórficos. As características dos solos hidromórficos, que via de regra são solos muito mal drenados e que geralmente apresentam-se encharcados e, dos próprios latossolos, que são solos bem drenados, mas quando sujeitos a processos de compactação e impermeabilização apresentam problemas quanto à capacidade de infiltração, vem justificar a presença dos menores índices do coeficiente $\mathrm{S}$ nestas regiões.

Quanto à influência da variação do tipo hidrológico dos solos no índice de escoamento superficial, como era de se esperar, esta pode ser considerada muito baixa na classe de edificação muito densa, com $85 \%$ de áreas impermeáveis. Esta classe apresenta uma malha urbana muito densa impedindo praticamente a infiltração da água no terreno, sendo o escoamento superficial, portanto, praticamente independente das características hidrológicas dos solos existentes.

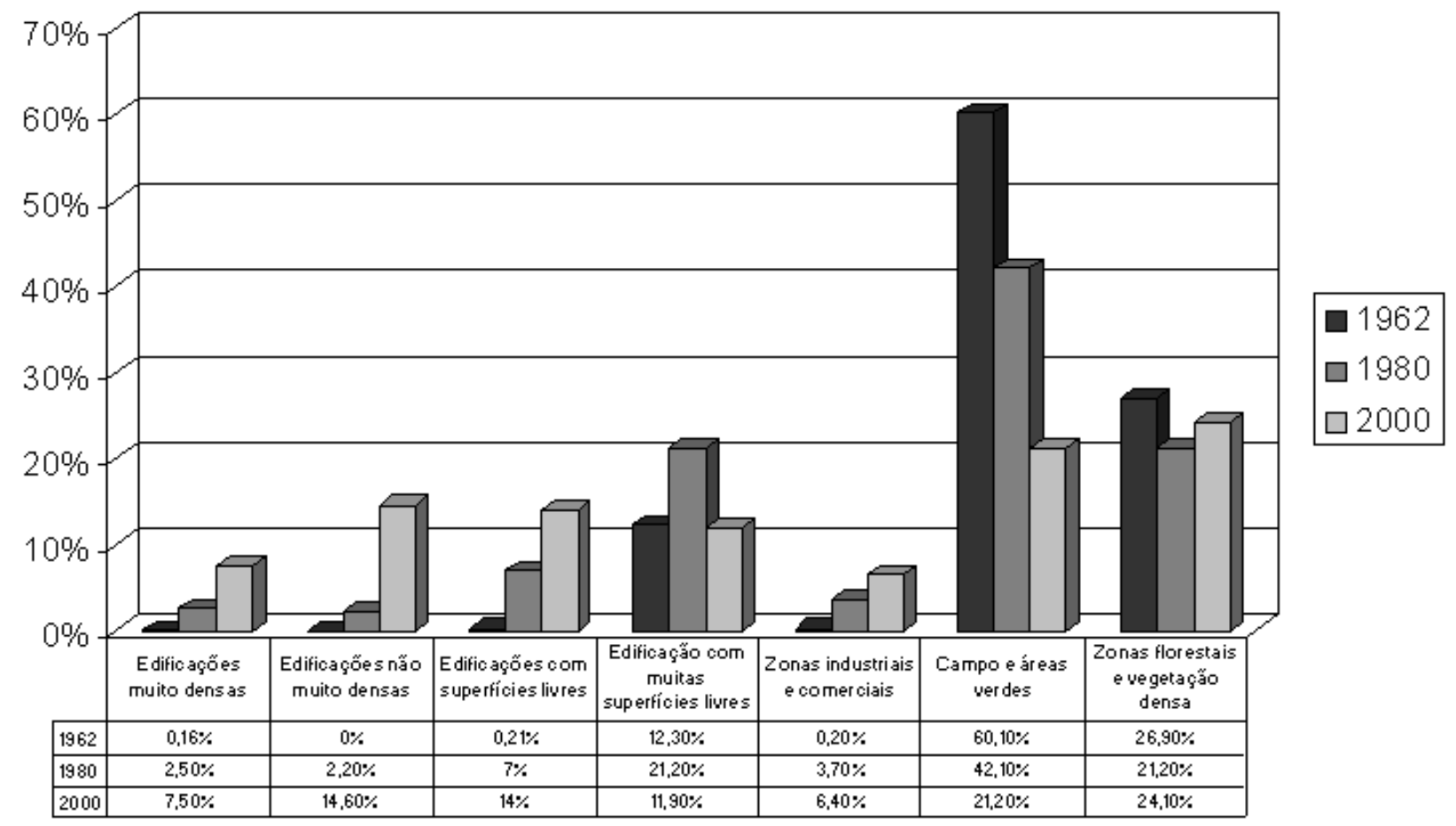

Figura 5 - Diferentes tipos de cobertura superficial do terreno para os anos de 1962, 1980 e 2000 ocorridos na bacia do rio Atuba. Surface covering comparative graphic for 1962, 1980 and 2000, showing the changes at Atuba basin. 


\section{Conclusão}

Por meio da análise multitemporal dos resultados obtidos para os coeficientes médios de escoamento superficial, da bacia hidrográfica do rio Atuba, concluiu-se que à medida que as áreas urbanas vão se intensificando no decorrer dos anos, ocorre a diminuição das áreas com os maiores índices de capacidade de armazenamento superficial do solo, em detrimento das áreas de menor capacidade de armazenamento e, conseqüente, acréscimo do índice de escoamento superficial.

A partir da quantificação das áreas permeáveis e impermeáveis do terreno, pode-se concluir que a bacia hidrográfica do rio Atuba sofreu um grande processo de impermeabilização urbana no período compreendido entre os anos de 1962 a 2000. Em 1962 as áreas permeáveis que ocupavam $95,6 \%$ da bacia, reduziram-se para $85,3 \%$ em 1980 e para $70 \%$ em 2000. Ao mesmo tempo, as áreas impermeáveis que ocupavam 4,5\% em 1962, aumentaram para $14,5 \%$ em 1980 e para $30 \%$ em 2000.

Comparando a variação do escoamento superficial, na condição de solos próximos à saturação, em relação à impermeabilização dos solos ocorrida entre 1962 a 2000, pode-se verificar que para uma mudança na taxa de impermeabilização dos solos de $4,5 \%$ com coeficiente $S$ igual a $41,81 \mathrm{~mm}$ para uma taxa de $30 \%$ de impermeabilização e coeficiente $S$ igual a $29,83 \mathrm{~mm}$, o valor C passou de 0,76 para 0,83 , ou seja, ocorreu um acréscimo de $9,2 \%$ entre este período.

Para condição de solos secos com coeficiente de armazenamento superficial do solo de 192,31mm em 1962 e $144,11 \mathrm{~mm}$ em 2000 e, mesma taxa de impermeabilização, o valor médio de $C$ passou de 0,33 em 1962, para 0,47 em 2000 , aumentando $42,4 \%$. Já em solos com condição média de saturação e coeficiente de armazenamento de 93,05mm em 1962 e 65,44mm no ano de 2000, o valor de $C$ de 0,58 em 1962 eleva-se para 0,68 em 2000 , com um acréscimo de $17,2 \%$.

Os resultados obtidos durante o trabalho deixam bem evidente a correlação existente entre o aumento da impermeabilização do solo, diminuição da capacidade de armazenamento e aumento do coeficiente de escoamento superficial. As áreas com maior percentagem de impermeabilização, com solo do tipo $D$, após eventos de chuvas intensas, apresentam menor capacidade de armazenamento e maior coeficiente de escoamento superficial do que as áreas com baixa percentagem de impermeabilização e solos do tipo $C$.

Os coeficientes de escoamento superficial médio da bacia do rio Atuba calculados para 1962, 1980 e 2000 nas condições hidrológicas de umidade III, ou seja, para solos próximos da saturação, indica que foi mais baixa a variação destes valores em um período de 40 anos, do que para as demais condições de umidade antecedentes analisadas. Essa baixa variação do coeficiente $C$ está condicionada a própria umidade antecedente do solo próxima à saturação e ao processo de urbanização, que avançou, principalmente em sua jusante, sobre um terreno naturalmente mal drenado de acordo com os aspectos geomorfológicos, topográficos, geológicos e pedológicos da região.

Os mapas de coeficientes de escoamento superficial possibilitam a visualização das regiões mais críticas ao escoamento das águas superficiais, nos três períodos analisados. A avaliação do tipo hidrológico de solo combinado com o tipo de cobertura superficial presente em cada classe de solo permitiu concluir a importância de uma maior preservação da cobertura vegetal, na contenção do escoamento superficial, principalmente sobre os tipos de solos do grupo $D$ que são solos mais propícios a uma baixa infiltração.

A aplicação do método de do Soil Conservation Service (SCS), juntamente com a utilização de técnicas de tratamento de dados em ambiente SIG, permitiu perceber que o coeficiente de escoamento superficial na bacia hidrográfica do rio Atuba é significativamente dependente dos tipos e das variações, ao longo do tempo de do espaço, da cobertura superficial do terreno e dos outros elementos físicos que o envolvem como: capacidade de armazenamento, infiltração e condições de umidade antecedente dos solos.

Agradecimentos: À Coordenação de Aperfeiçoamento de Pessoal de Nível Superior - CAPEs pela bolsa de doutorado, ao Conselho Nacional de Desenvolvimento Científico e Tecnológico - CNPq pela bolsa de doutorado sanduíche no exterior e ao Centro di Geotecnologie della Università degli Studi di Siena pelos conhecimentos e equipamentos utilizados durante a fase de fotointerpretação digital.

\section{Referências bibliográficas}

CHOW V.T., MAIDMENT D.R., MAYS L.W. 1988. Applied Hydrology. 1 ed. New York, McGraw Hill, $572 \mathrm{p}$.

EMBRAPA - EMPRESA BRASILEIRA DE PESQUISA AGROPECUÁRIA e IAPAR -INSTITUTO AGRONÔMICO DO PARANÁ. 1984. Levantamento de Reconhecimento dos Solos do Estado do Paraná: Tomo-I. Convenio EMBRAPA/SUDESUL/ Governo do Estado do Paraná/IAPAR, Londrina - Paraná, $412 \mathrm{p}$.

EMBRAPA - EMPRESA BRASILEIRA DE PESQUISA AGROPECUÁRIA e IAPAR -INSTITUTO AGRONÔMICO DO PARANÁ 1984. Levantamento de Reconhecimento dos Solos do Estado do
Paraná: Tomo-II. Convenio EMBRAPA/SUDESUL/Governo do Estado do Paraná/IAPAR, Londrina - Paraná, $791 \mathrm{p}$.

EMBRAPA - EMPRESA BRASILEIRA DE PESQUISA AGROPECUÁRIA e IAPAR -INSTITUTO AGRONÔMICO DO PARANÁ 1984. Carta de Solos do Levantamento e Reconhecimento dos Solos do Estado do Paraná. Londrina (PR), escala 1:600.000.

FENDRICH R., OBLADEN N.L., AISSE M.M., GARCIAS C.M. 1997. Drenagem e Controle da Erosão Urbana. 1 ed. Curitiba, Champagnat, 125-194 p. 
GENZ F., TUCCI C.E.M. 1995. Infiltração em Superfícies Urbanas. RBE- Rev. Bras. de Engenharia/ ABRH - Associação Brasileira de Recursos Hídricos. Porto Alegre, 13(1), 77- 103.

PROGRAMA SPRING 2005. INPE - Instituto de Pesquisas Espaciais, versão 4.2: Tutorial, São José dos Campos - SP, 1 CD-ROM.

IPH-UFRGS., UFPel., DFIS-FURG 2004. IPH-S1: Manual de Fundamentos. Porto Alegre, versão preliminar.

OSTA A.J.S.T..A. 1997. Influência da Urbanização no Comportamento Hidrológico de Bacias de Drenagem Município do Rio de Janeiro - RJ. In: VII Simpósio Brasileiro de Geografia Física Aplicada e I Fórum Latino-Americano de Geografia Física Aplicada. Curitiba, Departamento de Geografia - UFPR, Anais, vol. 2, 1 CD-ROM.

SALAMUNI E. 1998. Tectônica da Bacia Sedimentar de Curitiba PR. Inst. de Geociências e Ciências Exatas, UNESP, Rio ClaroSP, Tese de Doutorado, $211 \mathrm{p}$.

SEPL - SECRETARIA DE ESTADO DO PLANEJAMENTO E COORDENAÇÃO GERAL \& PROSAM - PROGRAMA DE SANEAMENTO AMBIENTAL DA REGIÃO METROPOLITANA DE CURITIBA. (1996) Parque e Controle de Cheias do Alto Iguaçu: Estudos Hidrológicos - Hidrodinâmicos do Rio Iguaçu. Curitiba PR, vol. 1 e 2.

TUCCI C.E.M. 1993. Hidrologia: Ciência e Aplicação. 1 ed. Porto Alegre, Editora da UFRGS, ABRH, EDUSP, 4, 942 p.

TUCCI C.E.M., PORTO R.L., BARROS M.T. 1995. Drenagem Urbana. 1 ed. Porto Alegre, Editora da UFRGS, 428 p. 